\author{
SERIES "RECENT DEVELOPMENTS IN PULMONARY INFECTIONS" \\ Edited by M. Woodhead and T. Schaberg \\ Number 4 in this Series
}

\title{
Burkholderia cepacia: current clinical issues, environmental controversies and ethical dilemmas
}

\author{
A.M. Jones, M.E. Dodd, A.K. Webb
}

Burkholderia cepacia: current clinical issues, environmental controversies and ethical dilemmas. A.M. Jones, M.E. Dodd, A.K. Webb. C) ERS Journals Ltd 2001.

ABSTRACT: Burkholderia cepacia is a plant phytogen and is known as a hardy and versatile organism.

Over the past two decades it has emerged as a pathogen in the cystic fibrosis (CF) community, with devastating effects. Pulmonary colonisation can lead to an accelerated decline in lung function. In some cases, it causes a rapid and progressive pneumonic illness termed "cepacia syndrome", which is untreatable and fatal.

B. cepacia is inherently resistant to multiple antibiotics and highly transmissible and virulent strains have been identified. $\mathrm{CF}$ patients colonised with the organism have to be segregated from their peers to try to prevent cross-infection.

However, the pathogenicity of $B$. cepacia is not limited to CF. Other groups, such as individuals with chronic granulomatous disease and immunocompromised patients are vulnerable and it has caused disease in healthy individuals. However, the agricultural and petrochemical industries are attempting to exploit properties of $\boldsymbol{B}$. cepacia for use as a biopesticide and biodegradation agent.

This article provides an up to date review of clinically based literature on the Burkholderia cepacia complex, highlighting clinical management issues for both cystic fibrosis and non-cystic fibrosis patients. The article also addresses the potential conflict between medicine and agriculture on plans to reintroduce strains of Burkholderia cepacia back into the environment.

Eur Respir J 2001: 17: 295-301.
Manchester Adult Cystic Fibrosis Unit, Wythenshawe Hospital, Southmoor Road, Manchester, UK.

Correspondence: A.K. Webb, Manchester Adult Cystic Fibrosis Unit, Wythenshawe Hospital, Southmoor Road, Manchester, UK.

Fax: 441612912080

Keywords: Agricultural industry Burkholderia cepacia

cystic fibrosis

petrochemical industry

pulmonary colonisation

Received: April 52000

Accepted after revision June 272000
The worst thing that can happen to a physician working in a cystic fibrosis $(\mathrm{CF})$ centre is to be confronted with a report from the microbiologist identifying Burkholderia cepacia for the first time in the sputum of a CF patient. The clinician then must inform the patient that they are infected with a transmissible organism that can potentially shorten survival by a decade [1]. The consequences for the $\mathrm{CF}$ patient are clearly much worse. Socially, they will be segregated from their peers. Clinically, it is likely that their disease will accelerate with increasing morbidity and mortality. Currently, eligibility for lung transplantation is a subject for debate and controversy [2]. It is recognized that a significant number of $B$. cepacia patients have a poor outcome following transplantation $[2,3]$.

Although the percentage of $\mathrm{CF}$ patients in a $\mathrm{CF}$ centre infected with B. cepacia is small, the literature output has increased exponentially over the last five years. The main thrust of these papers has concentrated upon taxonomy and microbial classification. This article will cover current knowledge of these areas, concentrating on their impact on clinical management of $B$. cepacia positive patients.

Hospitals are being increasingly recognised as dangerous places for cross-infection, either between patients or from the hospital environment. Nosocomial infections can occur, potentially with multidrugresistant organisms, including methicillin-resistant Staphylococcus aureus, Enterococcus, Pseudomonas and sometimes Aspergillus species. B. cepacia can now be added to this list, following recent reports describing the organism cross-infecting non-CF hospitalised patients with resultant morbidity [4]. The impact of this knowledge is discussed for both hospitalised $\mathrm{CF}$ and non-CF patients.

B. cepacia is also a biopesticide and has potential use for protecting crops. This environmental application is an area of potential conflict between the agriculturalists and scientists, as to whether a human pathogen should

Previous articles in this series: No.1: M.R. Hammerschlag. Chlamydia pneumoniae and the lung. Eur Respir J 2000; 16: 1001-1007. No. 2: S. Ewig, H. Schäfer, A. Torres. Severity assessment in community acquired pneumonia. Eur Respir J 2000; 16: 1193-1201. No. 3: L.P. Nicod, J-C. Pache, N. Howarth. Fungal infections in transplant recipients. Eur Respir J 2001; 17: 133 - 140. 


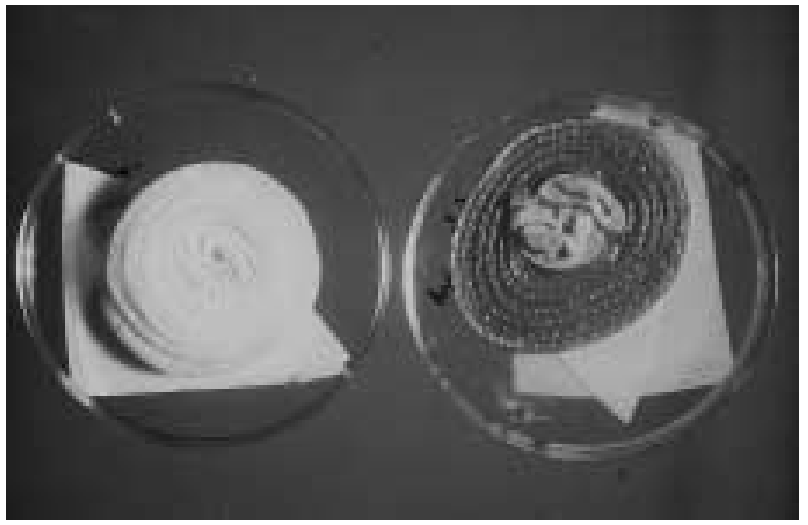

Fig. 1. - Two onions; the onion on the right of the photograph has been inoculated with Burkholderia cepacia, causing onion rot.

be placed in the environment [5]. The beneficial uses of B. cepacia outside the medical field are discussed.

\section{Historical}

The organism, a gram-negative motile rod, was first described by BuRKHOLDER [6] in 1950 as a plant pathogen and a cause of onion rot (fig. 1). Although hospital outbreaks in non-CF patients had been previously described, it was not until the early 1980s that an increasing incidence and prevalence of $B$. cepacia isolates were noted in North American CF centres $[7,8]$. These reports also described an increased morbidity and mortality in those patients infected with B. cepacia. In particular, the authors described "cepacia syndrome", when patients succumbed rapidly to a pneumonic illness with high temperatures and respiratory failure unlike any clinical situation found with other $\mathrm{CF}$ pathogens (fig. 2). The reduction of incidence by one centre using strict infection control measures suggested that person-to-person transmission was the main factor for cross-infection [9]. The proof of cross infection occurring both in hospitals and in the community was established in seminal papers by LiPumA and coworkers [10, 11] and Govan et al. [12], which showed patients shared the same strain of organism. It is against this background of knowledge that an enormous amount of research has been undertaken in the last decade into the microbiology of $B$. cepacia and how this information can be translated into therapeutic benefit for $\mathrm{CF}$ patients infected with $B$. cepacia.

\section{Microbiology and taxonomy}

B. cepacia has various characteristics that set it aside from other CF pathogens. It is highly transmissible, has inherent resistance to multiple antibiotics and is associated with greater virulence; it is these combined factors which make the management of $B$. cepacia patients so difficult. The organism has an unusually large genetic make up with a total DNA content greater than 7 megabases and as many as three megabase-sized

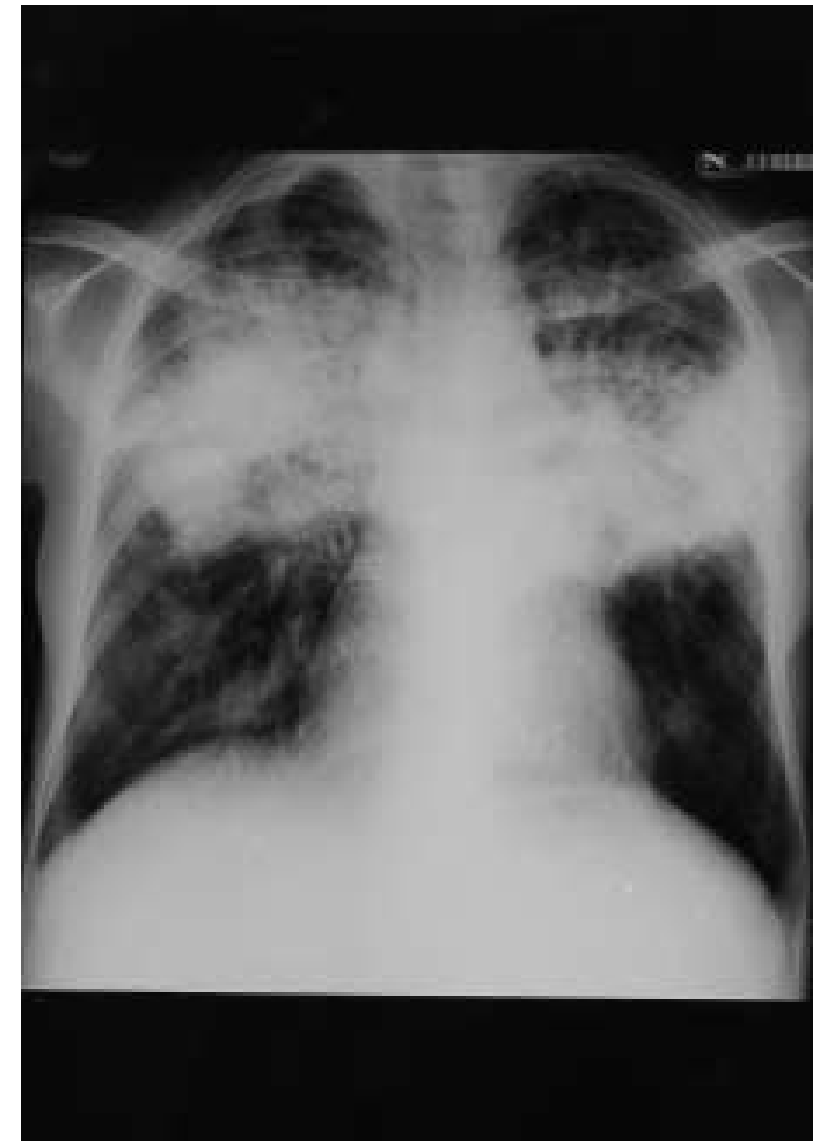

Fig. 2. - Chest radiograph showing typical appearances of the cepacia syndrome.

replicons [13]. This large genetic make up accounts for its microbiological versatility.

Because of the high rate of cross-infection with $B$. cepacia and associated virulence it has become increasingly important to correctly identify the organism. It is accurate to say that a large $\mathrm{CF}$ centre is crucially dependent upon the quality of its microbiology service. $B$. cepacia can be difficult to isolate. There are established media and laboratory protocols for the culture and identification of B. cepacia [14]. However, unequivocal identification of $B$. cepacia by commercial systems can present difficulties as existing selective media can support the growth of other gram-negative bacilli, such as Alcaligenes xylosoxidans, Stenotrophomonas maltophilia and Comamonas acidovorans. It is crucial that the laboratory uses established techniques and that the results are valid, reproducible and reliable. Inaccuracies, delay in microbiological diagnosis and the production of false positive and equally false negative results can have devastating clinical consequences. An unidentified B. cepacia positive patient will remain in the general $\mathrm{CF}$ clinic, continuing to pose a risk of crossinfection to other patients. A recently developed new selective medium has increased the level of identification of $B$. cepacia isolates [15]. This naturally raises concerns that in a large $\mathrm{CF}$ clinic there may be unidentified $B$. cepacia colonisation of some patients. 
Difficulties in accurately identifying B. cepacia and the realisation that there are different $B$. cepacia organisms (now known as the $B$. cepacia complex) has led to the development of molecular taxonomic analyses which place different $B$. cepacia strains into groups known as genomovars. Initially, VANDAMME [16] used molecular techniques to analyse whole cell proteins and DNA-DNA hybridizations to separate isolates simply identified as $B$. cepacia into four new Burkholderia species. Currently, on the basis of identifying new strains of $B$. cepacia there are now seven genomovar groups. An excellent review of the different groups has recently been published [17]. However, having separated the $B$. cepacia complex into genomovars, one has to ask whether this information is clinically useful. Does genomovar placement influence clinical practice. The main questions one asks when a patient becomes infected with $B$. cepacia is how virulent is the organism for that patient and is it transmissible to other patients? Currently that question is unanswered by genomovar status, but the most transmissible and virulent $B$. cepacia pathogens are placed in genomovar III. However transmissibility and virulence are not the same thing. Burkholderia gladioli, also a member of the Burkholderia species and supposedly nontransmissible, is difficult to separate from B. cepacia [18] and yet can cause gross thoracic

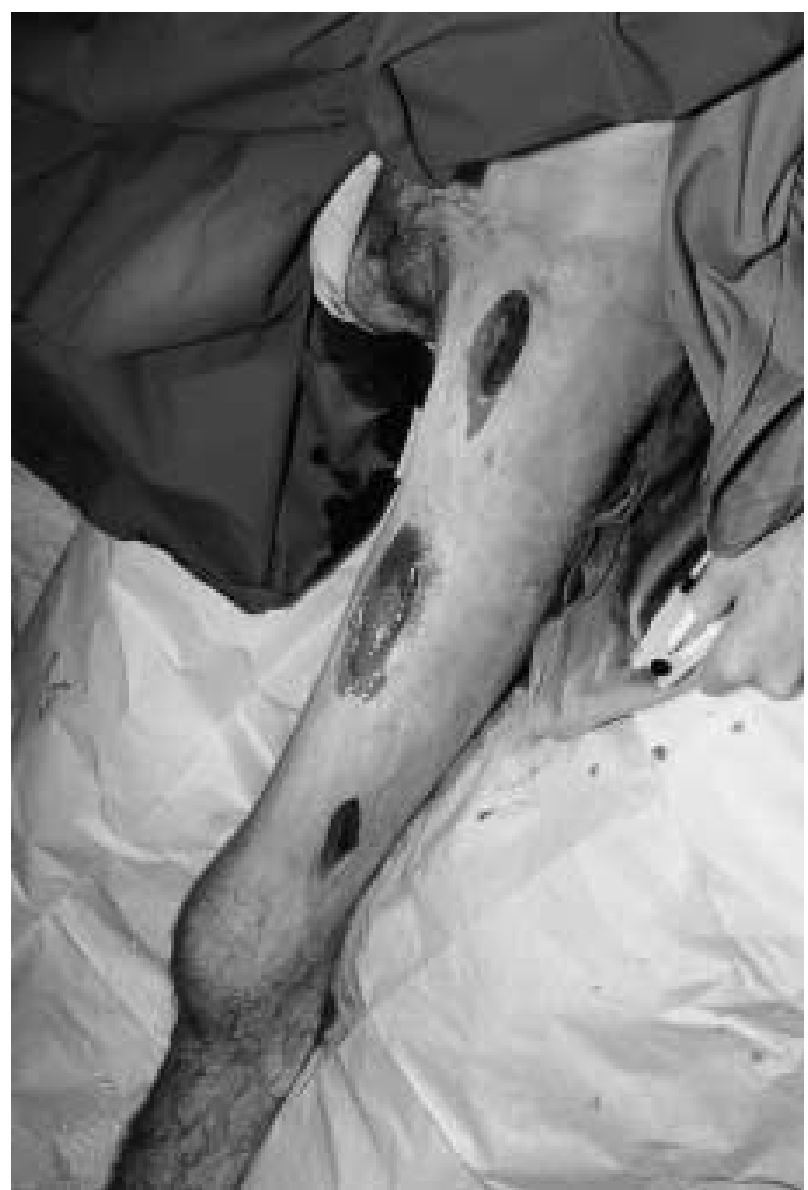

Fig. 3. - Surgical incision and exploration of a Burkholderia gladioli leg abscess. and extra thoracic disease (fig. 3). The B. cepacia strain responsible for the first described UK case of the "cepacia syndrome" in a young girl did not carry the cable pilus gene and did not transfer to her sibling [19]. Basically, genomovar status is a useful template to categorise organisms that make up the B. cepacia complex. However, the most clinically damaging pathogens are increasingly grouped in genomovar III which does not necessarily translate into useful clinical information in the $\mathrm{CF}$ clinic.

\section{Virulence and transmissibility}

An enormous amount of research has been undertaken to define those virulence factors, expressed by $B$. cepacia, which interact with the host, and account for the greater morbidity and mortality associated with this pathogen. Amongst many laboratory defined virulence factors, endotoxin has been clearly shown to have a role in the pathogenesis of B. cepacia infection. Lipopolysaccharide from clinical isolates has endotoxin activity and the capacity to induce tumour necrosis factor-alpha $(\mathrm{TNF}-\alpha)$ levels over nine times more than endotoxin extracted from Pseudomonas aeruginosa [20]. This conforms to the evidence that $\mathrm{CF}$ infected $B$. cepacia patients, when compared with $P$. aeruginosa colonised patients, have an up-regulated inflammatory response when measuring plasma neutrophil elastase [21]. Elegant microbiological studies in transgenic mice showed that nearly $70 \%$ of $\mathrm{CF}$ mice exposed to $B$. cepacia died from a more severe-bronchopulmonary infection than control animals [22]. Nitric oxide (NO) and hydrogen peroxide are important bacteriocidal mediators in lung defence against B. cepacia [23]. Inducible NO synthetase is deficient in the bronchial epithelium of $\mathrm{CF}$ patients. The lack of NO in the lungs of CF patients may contribute to their susceptibility to B. cepacia as a pulmonary pathogen.

One does not have to look very hard to observe that the clinical decline is overall greater for B. cepacia than $P$. aeruginosa infected patients. There is an accelerated decline in spirometry and nutritional status (the two main survival prognostic factors), with patients dying a decade earlier than their peers $[24,25]$. The organism can also cause prolonged temperatures and a terminal disease ("cepacia syndrome"), characterised by a confluent bronchopneumonia and septicaemia which can result in death over a period of days rather than months, and is unlike any clinical situation seen with $P$. aeruginosa. It would appear that $\mathrm{CF}$ patients therefore have either an exaggerated or defective response to infection with $B$. cepacia, which is much greater than those patients infected with $P$. aeruginosa. B. cepacia, when it infects non-CF patients, can produce severe disease. However, these patients are often clinically compromised and once their primary disease is treated they can eradicate $B$. cepacia.

Awareness of the increasing number of CF patients acquiring B. cepacia in CF clinics in North America led to the appreciation that the organism was cross infecting between patients [7, 8]. More recent work has shown that transmissibilty is strain dependent and different typing systems have defined an epidemic strain 


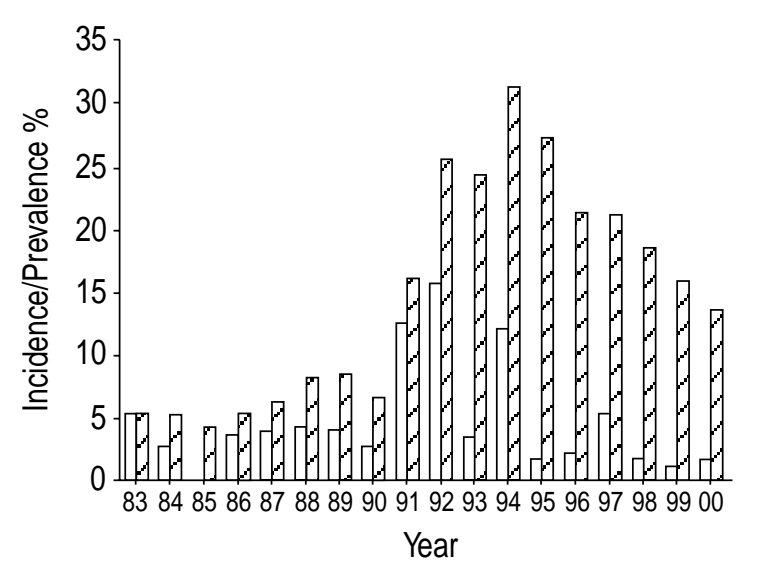

Fig. 4. - Incidence (new cases; $\square$ ) and prevalence (total cases; 『) rates for Burkholderia cepacia in the Manchester Adult Cystic Fibrosis (CF) Unit 1983-2000. From 1991-1992, the ET12 epidemic strain was identified in B. cepacia isolates in the Manchester unit and the incidence rate for $B$. cepacia increased. A partial segregation policy for $B$. cepacia positive and B. cepacia negative CF patients was introduced in the unit in 1992, with a subsequent fall in the incidence rate for 1993. However, the incidence rate increased again in 1994, demonstrating failure of the policy of partial segregation. It was following the introduction of a strict segregation policy for $B$. cepacia positive and $B$. cepacia negative CF patients in 1994 that the incidence rate for $B$. cepacia fell and has remained low. The continuing fall in prevalence of B. cepacia on the Manchester Unit is in relation both to a lower incidence rate and is also a reflection of the virulence of the organism as a pathogen in the $\mathrm{CF}$ community, with decreased survival rates for $\mathrm{CF}$ patients colonised by $B$. cepacia.

with a strong transatlantic lineage [12, 26-28]. This epidemic strain is identified by two markers, the cable pilus gene and a conserved $1.4 \mathrm{kbp}$ DNA fragment. There are other, well described transmissible strains of B. cepacia [29], but it is the epidemic strain known as ET (Edinburgh/Toronto) 12 which has caused the most concern, due to its apparently greater virulence. It has an almost total resistance to antibiotics and is strongly associated with the "cepacia syndrome". This has been highlighted in a recent report when the epidemic ET12 strain was transmitted to five $\mathrm{CF}$ patients with other strains of B. cepacia [30]. Four of the five CF patients cross-infected with the epidemic strain died, three from the lethal "cepacia syndrome". It is now recommended practice to segregate $\mathrm{CF}$ patients in cepacia clinics by their strain pattern [31]. In the Manchester Adult CF Unit, the incidence of $B$. cepacia increased with the emergence of the epidemic ET12 strain (fig. 4). A policy of partial segregation failed, and it was not until a strict segregation policy was introduced that the annual incidence rate of $B$. cepacia fell. The introduction of this policy has further increased the feeling of isolation in $\mathrm{CF}$ patients infected with $B$. cepacia. Of concern, but not discussed in the literature is whether all crossinfecting strains of $B$. cepacia have been identified. In the Manchester adult $\mathrm{CF}$ unit there are approximately 20 patients who have a $B$. cepacia without an identifiable strain marker. Do they all harbour their own specific $B$. cepacia pathogen which does not pose a threat to other CF B. cepacia positive patients, or is it like the $\mathrm{CF}$ gene where new mutations are frequently being identified?

\section{Clinical care of cystic fibrosis patients infected with Burkholderia cepacia}

Care of $\mathrm{CF}$ patients is best delivered from a $\mathrm{CF}$ centre and is associated with better nutritional status and spirometry [32]. However, there is a greater risk for cross-infection with B. cepacia at a CF centre. Despite the implementation of stringent segregation policies, it is unavoidable that $\mathrm{CF}$ patients will sometimes meet by chance, for instance in lifts, the hospital shop or inadvertently at outpatient appointments for different medical disciplines, such as obstetrics, gastroenterology and general surgery. B. cepacia positive CF patients should have the same clinical service as non-cepacia patients. As inpatients, they should have their own rooms, but on a separate ward. They should attend a specific cepacia outpatient clinic, with appointment times further designed to allow segregation by strain pattern.

Attention should be paid to nutrition. Intervention with nasogastric or gastrostomy feeding should be introduced early if there is difficulty in sustaining weight. Sustained temperatures (usually sputum load related) with an infective exacerbation are common and symptomatically distressing. Very high dose aspirin $(1.5 \mathrm{~g}$ q.i.d. $)$ is often useful until antibiotics reduce sputum load. However, sometimes temperatures are related to extensive pneumonic consolidation rather than B. cepacia sputum load. Antibiotic therapy needs to be extremely aggressive; triple antibiotic combinations are more likely than double antibiotic combinations to be bactericidal against $B$. cepacia [33]. Intravenous septrin also has some benefit. Oral antibiotics can include combinations of ciprofloxacin, rifampicin, chloramphenicol and minocycline. There are, however, no clinical trials validating these regimes. Additionally there is concern about the unpredictable but common occurrence of antagonism (growth of an organism when a third antibiotic is added to a bactericidal combination of two antibiotics). The development of the cepacia syndrome (or "necrotizing cepacia"), characterised by a sustained temperature and confluent chest radiograph shadowing, signals a currently untreatable clinical situation. The Manchester Adult CF Unit has used immunomodulatory agents such as methylprednisolone, immunoglobulins and cyclosporin as part of the treatment regime for patients with cepacia syndrome; these have occasionally improved the situation, but only for a few days.

The most difficult clinical situation is planning transplantation for $\mathrm{CF}$ patients infected with $B$. cepacia $[2,34]$. In times of increasing organ donor shortage and reports of a $75 \%$ mortality rate in $B$. cepacia patients following transplantation there has been increasing reluctance to list these patients $[3,34]$. One option may be to list them earlier in a more stable state but it can be argued ethically (or legally) that every patient has the right to be considered for transplantation if there is some chance of benefit [35]. Although there are reports of a high mortality rate for $B$. cepacia positive patients post-transplantation [3, 36], there are other studies which show benefit or no difference in survival terms for $B$. cepacia positive and $B$. cepacia negative patients [36, 37]. 


\section{Infection with Burkholderia cepacia without cystic fibrosis}

The pathogenicity of $B$. cepacia is not limited to individuals with $\mathrm{CF}$. Another vulnerable group are patients with chronic granulomatous disease in whom infection with $B$. cepacia has been associated with a fatal outcome $[38,39]$. B. cepacia has been recognised as causing fatal disease in healthy individuals $[40,41]$. In hospitals, B. cepacia has been found to contaminate antiseptics, disinfectants, nebuliser solution, and dextrose solution [42-44]. Contamination of a nebuliser solution resulted in patients becoming infected with $B$. cepacia and contamination of a dextrose infusion solution resulted in seven patients developing $B$. cepacia septicaemia. These reports over the last decade highlight the opportunistic nature of $B$. cepacia and its occasional ability to contaminate the hospital environment and infect immunocompromised and more rarely, healthy individuals.

However, of greater concern are two recent reports demonstrating cross-infection of epidemic B. cepacia from $\mathrm{CF}$ patients to non-CF individuals. The first case describes a mother developing severe bronchiectasis having been infected by her CF B. cepacia positive child [45]. This case is extremely unusual but raises the concern, although small, that carers of $\mathrm{CF}$ patients are not entirely free from risk of cross-infection with virulent pathogens. Of considerable concern is a recent report describing cross-infection by a single dominant clone of $B$. cepacia between patients with and without cystic fibrosis [4]. Isolates of B. cepacia were obtained from sputum (228), intravenous catheters (11), urine (10), wounds (10) and other miscellaneous sites (11) from 245 critically ill non-CF patients on intensive care units. In the same hospital $23 \mathrm{CF}$ patients had isolates for $B$. cepacia. Although the hospital had isolation policies for $B$. cepacia positive $\mathrm{CF}$ individuals, this policy did not apply to $B$. cepacia positive non-CF patients who were in the same ward as other B. cepacia negative $\mathrm{CF}$ patients. $\mathrm{CF}$ patients with $B$. cepacia did not always follow the segregation rules. Thus $B$. cepacia cross-infected both ways between both groups of $\mathrm{CF}$ and non-CF patients. This report strongly supports a practice of segregating both $\mathrm{CF}$ and non-CF patients infected with $B$. cepacia. All these reports highlight the risk $B$. cepacia poses to all hospital patients and sometimes patients in the community.

\section{Agricultural role of Burkholderia cepacia?}

As detailed in this review, B. cepacia is a human pathogen. However, it is also a powerful pesticide and can eliminate many soil-borne plant pathogens [5]. It also plays a potential role as a biofertiliser for rice cultivated in low acidic, low fertile soils. It is not surprising that patents are being sought by the agricultural lobby for different strains of $B$. cepacia which can be used to enhance crop yields. Furthermore, scientists are also exploiting the diverse metabolic properties of B. cepacia to develop it as an agent for use in the bioremediation of contaminated environmental sites. The potential economic and ecological benefits are considerable. Widespread use would however, increase human exposure. Recently, evidence of a clonal relationship between one strain of $B$. cepacia causing onion rot and another isolated from respiratory secretions of a CF patient has been obtained, suggesting the same clone can be present in both types of niche (environmental and human pathogen) [46]. In addition, Burkholderia isolates have recently been cultured from rhizospheres in maize and wheat; taxonomic studies have identified these isolates as belonging in B. cepacia genomovar III. Although the virulence of environmental B. cepacia genomovar III isolates has yet to be determined, the most damaging $B$. cepacia human pathogens are all found in this particular genomovar group.

As stated earlier, B. cepacia has a large and complex genome. If $B$. cepacia strains were placed back deliberately into the environment there is the potential risk of horizontal gene transfer with, perhaps, the evolution of more virulent human pathogens. Recently insertion sequences within Burkholderia pseudomallei have been identified in $B$. cepacia, including an isolate belonging to the epidemic strain. It is currently impossible to identify strains of $B$. cepacia that can be used safely in agriculture, without causing a hazard to human health. This is clearly an area for conflict of interest between medicine and agriculture.

\section{Conclusion}

This review has concentrated on current areas of interest regarding Burkholderia cepacia. Interest in this area is highlighted by the increase in publications by physicians and scientists, with over 700 articles published in the last decade. Although the effect upon cystic fibrosis patients has been devastating, it has also damaged non-cystic fibrosis patients and is causing conflict between medicine and agriculture. This difficult and versatile pathogen is likely to continue to cause problems over the next decade.

\section{References}

1. Fitzsimmons S. Cystic Fibrosis Foundation, Cystic Fibrosis Patient Registry report. Pediatr Pulmonol 1996; 21: $267-275$.

2. Webb AK, Egan J. Should patients infected with Burkholderia cepacia undergo lung transplantation. Thorax 1997; 52: 671-673.

3. Snell GI, de Hoyos A, Krajden M, Winton T, Maurer JR. Pseudomonas cepacia in lung transplant recipients with cystic fibrosis. Chest 1993; 103: 466-471.

4. Holmes A, Nolan R, Taylor R, et al. An epidemic of Burkholderia cepacia transmitted between patients with and without Cystic Fibrosis. J Infect Dis 1999; 179: $1197-1205$.

5. Holmes A, Govan J, Goldstein R. The agricultural use of Burkholderia (Pseudomonas) cepacia: a threat to human health? Emerg Infect Dis 1998; 4: 221-227.

6. Burkholder WH. Sour skin, a bacterial rot of onion bulbs. Phytopathology 1950; 40: 115-117.

7. Isles P, MacLusky I, Corey M, et al. Pseudomonas 
cepacia infection in cystic fibrosis: An emerging problem. J Pediatr 1984; 104: 206-210.

8. Thomassen MJ, Demko CA, Klinger JD, Stern RC. Pseudomonas cepacia colonisation among patients with cystic fibrosis. A new opportunist. Am Rev Resp Dis 1985; 131: 791 - 796.

9. Thomassen MJ, Demko CA, Doershuk CF, Stern RC, Klinger JD. Pseudomonas cepacia: Decrease in colonisation in patients with cystic fibrosis. Am Rev Resp Dis 1986; 134: 669-671.

10. LiPuma JJ, Mortensen JE, Dansen SE, et al. Ribotype analysis of Pseudomonas cepacia from CF treatment centres. J Pediatr 1988; 113: 859-862.

11. LiPuma JJ, Dansen SE, Nielson DW, Stern RC, Stull TL. Person-to-person transmission of Pseudomonas cepacia between patients with CF. Lancet 1990; 336: $1094-1096$.

12. Govan JRW, Brown PH, Maddison J, et al. Evidence for transmission of Pseudomonas cepacia by social contact in cystic fibrosis. Lancet 1993; 342: 15-19.

13. Rodley PD, Romling U, Tummler B. A physical genome map of the Burkholderia (Pseudomonas) cepacia type strain. Mol Microbiol 1995; 17: 57-67.

14. Kiska DL, Kerr A, Jones MC, et al. Accuracy of four commercial systems for identification of Burkholderia cepacia and other Gram-negative nonfermenting bacilli recovered from patients with cystic fibrosis. $J$ Clin Microbiol 1996; 34: 886-891.

15. Henry DA, Campbell ME, LiPuma JJ, Speert DP, Identification of Burkholderia cepacia isolates from patients with cystic fibrosis and use of a single new selective medium. J Clin Microbiol 1997; 35: 614-619.

16. Vandamme $\mathrm{P}$, Holmes $\mathrm{A}$, Vancanneyt $\mathrm{M}$, et al. Occurrence of multiple genomovars of Burkholderia cepacia in cystic fibrosis patients and proposal of Burkholderia multivorans species. Int J Syst Bacteriol 1997; 47: $1188-1200$.

17. Mahenthiralingam EM, Coenye T, Chung JW, et al. Diagnostically and experimentally useful panel of strains from the Burkholderia cepacia complex. J Clin Microbiol 2000; 38: 910-913.

18. Clode FE, Metherell LA, Pitt TL. Nosocomial acquisition of Burkholderia gladioli in patients with cystic fibrosis. Am J Respir Crit Care Med 1999; 60: $374-375$.

19. Glass S, Govan JRW. Pseudomonas cepacia: fatal pulmonary infection in a patient with cystic fibrosis. $J$ Infect 1986; 13: $157-158$.

20. Shaw D, Poxton IR, Govan JRW. Biological activity of Burkholderia (Pseudomonas) cepacia lipopolysaccharide. FEMS Immunol Med Microbiol 1995; 11 99- 106.

21. Downey DG, Dempster M, Martin J, et al. Relationship of Burkholderia cepacia to inflammatory markers in stable cystic fibrosis. Pediatr Pulmonol 1999, (S19): 311.

22. Davidson DJ, Dorin JR, McLachlan G, et al. Lung disease in the cystic fibrosis mouse exposed to bacterial pathogens. Nat Genet 1995; 9: 351-357.

23. Meng QH, Springall DR, Bishop AE, et al. Lack of inducible nitric oxide synthase in bronchial epithelium: a possible mechanism of susceptibility to infection in cystic fibrosis. J Pathol 1998; 184: 323 - 331.

24. Muhdi K, Edenborough FP, Gumery L, et al. Outcome for patients colonised with Burkholderia cepacia in a Birmingham adult cystic fibrosis clinic and the end of an epidemic. Thorax 1996; 51: 374-377.
25. Brown P, Butler S, Nelson J, Doherty C, Govan J, Greening A. Pseudomonas cepacia in adult cystic fibrosis: accelerated decline in lung function and increased mortality. Thorax 1993; 48: 425-426.

26. Sun L, Jiang RZ, Steinbach S, et al. The emergence of a highly transmissible lineage of $\mathrm{cbl}+$ Burkholderia cepacia causing cystic fibrosis epidemics in North America and Britain. Nat Med 1995; 1: 661-666.

27. Johnson WM, Tyler SD, Rozee KR. Linkage analysis of geographical and clinical clusters in Pseudomonas cepacia infections by multilocus enzyme electrophoresis and ribotyping. J Clin Microbiol 1994; 32: 924-930.

28. Mahenthiralingham E, Simpson DA, Speert DP. Identification and characterisation of a novel marker associated with epidemic Burkholderia cepacia strains recovered from patients with cystic fibrosis. J Clin Microbiol 1997; 35: 808-816.

29. Govan JRW, Hughes JE, Vandamme P. Burkholderia cepacia: medical taxonomic and ecological issues. J Med Microbiol 1996; 45: 395-407.

30. Ledson MJ, Gallagher MJ, Corkhill JE, Hart CA, Walshaw MJ. Cross infection between cystic fibrosis patients colonised with Burkholderia cepacia. Thorax 1998; 53: $432-436$.

31. Cystic Fibrosis Trust Infection Control Group. A statement on Burkholderia cepacia. Cystic Fibrosis Trust 1999.

32. Mahadeva $\mathrm{R}$, Webb $\mathrm{AK}$, Westerbeek $\mathrm{RC}$, et al. Clinical outcome in relation to care in centres specialising in cystic fibrosis: cross sectional survey. BMJ 1998; 316: 1771 - 1775 .

33. Aaron SD, Ferris W, Henry DA, Speert DP, MacDonald NE. Multiple combination bacteriocidal testing for patients with cystic fibrosis infected with Burkholderia cepacia organisms. Am J Respir Crit Care Med 2000; 161: 1206 - 1212.

34. Ramirez JC, Patterson GA, Winton TL, De Hoyos AL, Miller JD, Maurer JD. Bilateral lung transplantation for cystic fibrosis: The Toronto Lung Transplant Group. J Thorac Cardiovasc Surg 1992; 103: $287-294$.

35. Harris J. What is the good of health care? Bioethics 1996; 4: 269-291.

36. Egan JJ, McNeil K, Bookless B, et al. Post transplant survival of cystic fibrosis patients infected with Pseudomonas cepacia. Lancet 1994; 334: 552-553.

37. Flume PA, Egan TM, Paradowiski LJ, Detterbeck FC, Thomson JT, Yankaskas JR. Infectious complications of lung transplantation: impact of cystic fibrosis. Am J Respir Crit Care Med 1994; 149: $1706-1709$.

38. $\mathrm{O}^{\prime}$ Neil KM, Herman JH, Modlin JF, Moxon ER, Winklestein JA. Pseudomonas cepacia: An emerging pathogen in chronic granulomatous disease. $J$ Pediatr 1986; 108: $940-942$.

39. Lacey DE, Spencer DA, Goldstein A, Weller P, Darbyshire P. Chronic granulomatous disease presenting in childhood with Pseudomonas cepacia septicaemia. J Infect Dis 1993; 27: 301 - 304.

40. Wong S, Tam AY, Yung RW, Kwan EY, Tsoi NN. Pseudomonas septicaemia in apparently healthy children. Acta Paediatr Scan 1991; 80: 515-520.

41. Hobson R, Gould I, Govan J. Burkholderia (Pseudomonas) cepacia as a cause of brain abscesses secondary to chronic suppurative otitis externa. Eur J Clin Microbiol Infect Dis 1995; 41: 908 -911. 
42. Oie S, Kamiya A. Microbial contamination of antiseptics and disinfectants. Am J Infect Control 1996; 24: 389-395.

43. Reboli AC, Koshinski DO, Arias MS, Marks-Austen K, Stieritz D, Stull TL. An outbreak of Burkholderia cepacia lower respiratory tract infection associated with contaminated albuterol nebulization solution. Infect Control Hosp Epidemiol 1996; 17: 741 - 743.

44. Van Laer F, Raes D, Vandamme P et al. An outbreak of Burkholderia cepacia with septicaemia on a cardiology ward. Infect Control Hosp Epidemiol 1998; 19: $112-113$.

45. Ledson MJ, Gallagher MJ, Walshaw MJ. Chronic Burkholderia cepacia bronchiectasis in a non-cystic fibrosis individual. Thorax 1998; 53: 430-432.

46. Govan JRW, Balendreau J, Vandamme P. Burkholderia cepacia: friend and foe. ASM NEWS. March 2000 (in press). 